\title{
DOES INCOME MOBILITY EQUALIZE LONGER-TERM INCOMES? NEW MEASURES OF AN OLD CONCEPT
}

\author{
Gary S. Fields \\ Cornell University and IZA
}

This version: March, 2009

Forthcoming: Journal of Economic Inequality.

Direct correspondence to:

Gary S. Fields

John P. Windmuller Professor of International and Comparative Labor

Cornell University

Ithaca, NY 14853-3901 U.S.A.

Telephone: (1) 607-255-4561

Fax: (1) 607-255-4496

E-mail: gsf2@cornell.edu 


\begin{abstract}
This paper develops a new class of measures of mobility as an equalizer of longerterm incomes - a concept different from other notions such as mobility as timeindependence, positional movement, share movement, income flux, and directional income movement. A number of properties are specified leading to a class of indices, one easily-implementable member of which is applied to data for the United States and France. Using this index, income mobility is found to have equalized longer-term earnings among U.S. men in the 1970s but not in the 1980s or 1990s. In France, though, income mobility was equalizing throughout, and it has attained its maximum in the most recent period.
\end{abstract}

JEL Codes: C43, D31, J3, J6

Keywords: Income mobility, equalization, United States, France

\title{
ACKNOWLEDGMENTS
}

I am grateful to Kaushik Basu, François Bourguignon, Satya Chakravarty, Frank

Cowell, Samuel Freije, William Gale, Carol Graham, Robert Hutchens, George

Jakubson, Jesse Leary, David Newhouse, Efe Ok, Pierre Pestieau, Christopher Scott, Jacques Silber, Peyton Young, and a number of anonymous referees for helpful suggestions during the preparation of this paper. 


\section{The Notion of Income Mobility as an Equalizer of Longer-Term Incomes}

It has long been recognized that cross-sectional distributions of economic wellbeing (hereafter referred to as "income") provide an incomplete and perhaps distorted picture of longer-term economic well-being. Slemrod (1992), for instance, has maintained that what he graphically calls "time-exposure income" gives a better picture of inequality than does "snapshot income." In any given year, people may have incomes which are transitorily high or low for reasons such as unemployment, illness, youth, good or bad luck, or exceptional economic events. As Joseph Schumpeter once put it, the distribution of incomes is like the rooms in a hotel - always full but not necessarily with the same people (Schumpeter, 1955, p. 126; cited in Sawhill and Condon, 1992). Economic mobility studies provide information about changes of people among rooms and changes in the rooms themselves.

One of the primary motivations for economic mobility studies is to gauge the extent to which longer-term incomes are distributed more or less equally than are singleyear incomes. This perspective goes back to Milton Friedman (1962) who wrote:

Consider two societies that have the same distribution of annual income. In one there is great mobility and change so that the position of particular families in the income hierarchy varies widely from year to year. In the other, there is great rigidity so that each family stays in the same position year after year. Clearly, in any meaningful sense, the second would be the more unequal society.

More recent authors have argued similarly. For instance, Shorrocks (1978) has said:

"Mobility is regarded as the degree to which equalization occurs as the period is extended. This view captures the prime importance of mobility for economists." Atkinson, Bourguignon, and Morrisson (1992) write in a similar vein: "One of the reasons why mobility is of interest is that it reduces inequality in the lifetime sum of earnings relative to that in a single period." Krugman (1992) states: "If income mobility were very high, the degree of inequality in any given year would be unimportant, because 
the distribution of lifetime income would be very even . . . An increase in income mobility tends to make the distribution of lifetime income more equal." Jarvis and Jenkins (1998) put it thus: "To some people, greater inequality at a point in time is more tolerable if accompanied by significant mobility; mobility smoothes transitory variations in income so that 'permanent' inequality is less than observed inequality." Finally, Maasoumi (1998) has written, "Mobility should be of greater concern to policymakers and analysts than such other important concerns as inequality... What matters in this context is 'lifetime equity' rather than instantaneous equality."

We thus have an old, clear, well-defined, ethically-relevant concept: income mobility as an equalizer of longer-term incomes. What we as empirical researchers would want to know in a given context is the extent to which the mobility that takes place works to equalize longer-term incomes relative to the base, disequalizes longer-term incomes relative to the base, or has no effect.

Given this concept, we need a measure of it. Below, I review how the existing mobility measures treat such processes. Many measures treat other mobility concepts but not mobility as an equalizer of longer-term incomes. Two existing measures treat mobility as an equalizer of longer-term incomes but in different ways: Shorrocks (1978) by comparing the inequality of longer-term incomes relative to a weighted average of the inequalities of single-year incomes, not to the inequality of base-year incomes as is done here; and Chakravarty, Dutta, and Weymark (1985) by reaching the opposite ethical judgment from the one that I would want to draw.

\section{Equalization or Disequalization of Longer-Term Incomes: Standard Mobility}

\section{Measures and the Need for a New One}

\subsection{Notation}

The following notation is used in what follows. Each individual, indexed by 
$i=1,2, \ldots, n$, receives an income $y_{i}^{t}$ in period $t, t=1,2, \ldots, T$. Thus, a given situation $\mathbf{y}:=\left[y_{i}^{t}\right]$ is an $n \times T$ matrix, where $\mathbf{y}_{i}=\left[y_{i}^{1}, \ldots, y_{i}^{T}\right]$ and $\mathbf{y}^{t}:=\left[\begin{array}{c}y_{1}^{t} \\ \cdot \\ \cdot \\ y_{n}^{t}\end{array}\right]$ represent respectively the income profile of individual $i$ and the snapshot distribution in period $t$. Define $Y_{i}:=\sum_{t=1}^{T} y_{i}^{t}$ to be the total income received by individual $i$ over $T$ periods and $\mathbf{Y}:=\left[\begin{array}{c}Y_{1} \\ \cdot \\ \cdot \\ Y_{n}\end{array}\right]$ to be the distribution of these longer-term incomes. Finally, adopt the notational convention of arraying income recipients in an arbitrary order in the base-year distribution (j), keeping these identified individuals in the same position in the final-year distribution ( $\mathrm{k}$ ), and denoting the movement from a base-year personalized vector to a final-year personalized vector by $y^{j^{\prime}} \rightarrow y^{k^{\prime}}$, which specializes in the two-period case to $y^{1^{\prime}} \rightarrow y^{2^{\prime}}$.

\subsection{Why Equalizing Longer-Term Incomes Is Not the Same as Equalizing Single-Period Incomes}

As has been noted by many authors going back at least as far as Friedman (1962), equalization of longer-term incomes is a fundamentally different concept from equalization of single-period incomes. The following simple example illustrates the difference.

Suppose we draw samples of two persons from an economy in a base year and a final year and measure the incomes of each person in each of the two years. Let the distribution of income in the base year be $\mathbf{y}^{1^{\prime}}=(1,3)$, and in the final year, $\mathbf{y}^{2^{\prime}}=(1,5)$. In a very straightforward sense, it is clear that the movement from $\mathbf{y}^{1^{\prime}}$ to $\mathbf{y}^{2^{\prime}}$ has disequalized single-period incomes. 
What about longer-term incomes? The two possible patterns of longitudinal income changes consistent with $\mathbf{y}^{1^{\prime}} \rightarrow \mathbf{y}^{2^{\prime}}$ are

$$
\mathrm{I}:(1,3) \rightarrow(1,5)
$$

and

$$
\text { II: }(1,3) \rightarrow(5,1)
$$

If we take as our measure of longer-term income the average income of each individual over the period in question, as is used in much of the literature on the permanent income hypothesis of Friedman (1957), the distribution of longer-term incomes in Case I is $\boldsymbol{Y}^{I^{\prime}}=[1,4]$, and in case II, it is $\boldsymbol{Y}^{I I^{\prime}}=[3,2]$.

A straightforward way of gauging whether the underlying mobility processes have equalized or disequalized the distribution of longer-term income in each case is to compare the inequality of $\boldsymbol{Y}^{I}$ and $\boldsymbol{Y}^{I I}$ with the inequality of their common base year income distribution $\boldsymbol{y}^{1}$. Why $\boldsymbol{y}^{1}$ ? Because it is customary in economics to relate changes to the starting point, for example, in calculating economic growth rates, or more generally, in determining whether an economic magnitude has changed for the better or the worse. For any reasonable concept of inequality,it is clear that $\boldsymbol{Y}^{I}$ is more unequal than $\boldsymbol{y}^{1}$ while $\boldsymbol{Y}^{I I}$ is more equal than $\boldsymbol{y}^{1}$. Since both $\boldsymbol{Y}^{I}$ and $\boldsymbol{Y}^{I I}$ are derived from the same initial vector of anonymous incomes $\mathbf{y}^{1^{\prime}}=(1,3)$ and final vector of anonymous incomes $\mathbf{y}^{2^{\prime}}=(1,5)$, it follows that changes in the inequality of single-period income give no information whatsoever about whether longer-term incomes are more equally distributed or less equally distributed than initial incomes. In this sense, the two are distinct concepts.

This example also makes clear why the literature on the redistributive impact of taxes and public expenditures (Lambert, 2001; Bénabou and Ok, 2001) does not offer guidance on how to measure the extent of equalization and disequalization of mobility processes. Both in the case of $(1,3) \rightarrow(1,5)$ and in the case of $(1,3) \rightarrow(5,1)$, period 2 income is obviously more unequally distributed than period 1 income, but to say whether 
mobility equalizes longer-term incomes vis-à-vis initial incomes or disequalizes them, we need to compare the joint distribution of period 1 and period 2 incomes with the distribution of period 1 incomes alone. By contrast, the literature on the equalizing impact of taxes involves comparing the post-tax distribution 2 with the pre-tax distribution 1. The difference between these two structures is the reason that the results from the literature on the redistributive effects of taxes cannot be borrowed and applied here.

\subsection{Distinguishing Mobility when 'Gates gains' Compared with Mobility} when 'Gates loses'

Starting with a given vector of base-year incomes, suppose that all persons except one keep the same income as before. The one exception is the richest person in the economy (call him "Gates"), whose income rises by 50\%: $(100,200,20000) \rightarrow(100$, 200, 30000). By any of the standard definitions of income inequality, this "Gates-gains"

process increases inequality between period 1 and period 2, but that is not the issue raised by the authors quoted in the introduction. The issue is how to characterize the mobility that has taken place.

What do the usual mobility measures say about this process? Many mobility measures in common use - including the trace of the quantile transition matrix, the coefficient of rank correlation, the mean number of absolute ranks changed, and many others - would record no mobility in this process. This is because these measures are all based on quantiles of an income transition matrix, none of which change as long as everyone maintains the same rank in the income distribution as before. What these measures measure is positional movement, and they rightly record that there is none of it in the Gates-gains process as long as Gates keeps his \#1 position and all other incomes are unchanged. 
What about other mobility concepts in the Gates-gains case? The various mobility concepts are discussed in Atkinson, Bourguignon, and Morrisson (1992), Maasoumi (1998), Fields and Ok (1999a), and Morgan (2005), among others, and are distinguished in Fields (2001, 2008). Time-dependence (measured, for example, by 1-r $\left.\left(y_{1}, y_{2}\right)\right)$ is said to be perfect (or equivalently, time-independence is said to be zero) if all final-year incomes are perfectly predictable from base-year incomes. But because this is not the case when Gates gains, we have a non-zero amount of time-independence. Sharemovement takes place if and only if some recipients' income shares change, which is clearly the case here; thus, an index of share movement such as $(1 / n) \Sigma\left|s\left(y_{2 i}\right)-s\left(y_{1 i}\right)\right|$, where $s($.$) denotes i$ 's share of total income, would be strictly positive. Non-directional income movement (also known as "income flux") arises whenever somebody's income fluctuates; that has happened here, as would be recorded, for example, by the Fields-Ok non-directional index $(1 / n) \Sigma\left|y_{2 i}-y_{1 i}\right|$. Directional income-movement, gauged for example by the Fields-Ok directional index $(1 / n) \Sigma\left(\log y_{2 i}-\log y_{1 i}\right)$, is positive when someone experiences an income gain, which has also happened. And the quasi-Paretian approach to mobility as welfare change (viz., an increase in any income holding others constant is deemed to be welfare-improving) would judge that when Gates gains, the mobility that has taken place has raised welfare. Column (1) of Table 1 displays the changes in measures of each of these concepts when Gates gains.

While these various concepts, and the measures of them, tell us different things about the Gates-gains process, none indicates that the change $(100,200,20000) \rightarrow$ $(100,200,30000)$ disequalizes longer-term incomes relative to the base. So if equalization of longer-term incomes is what we are interested in, the mobility concepts and measures just reviewed do not measure it.

Consider what would happen if, instead of Gates gaining 50\%, Gates were to lose $50 \%$. Clearly, such a change should equalize longer-term incomes relative to base year incomes. 
Putting the preceding judgments together, any measure of equalization of longerterm incomes relative to base-year incomes should:

i) Be negative if the richest person gets richer, holding other incomes constant.

ii) Be positive if the richest person gets poorer, holding other incomes constant.

iii) Equal zero if the richest person 's and everybody else's incomes are unchanged.

These three conditions are in fact the defining characteristics of a measure of mobility as an equalizer of longer-term incomes when only the richest person's income changes. These notions are generalized in Section 3 to changes in incomes of persons other than the richest.

The second column of Table 1 makes calculations similar to those of column (1) for the Gates-loses case. Comparing the two columns of Table 1, we see that none of the mobility measures in Table 1, or the concepts they represent, fulfills conditions i) - iii). Positional-movement measures are zero in both cases. Time-independence, sharemovement, and non-directional income movement measures are positive both for Gatesgains and for Gates-loses, even though inequality rises when Gates gains and falls when Gates loses. Two measures change sign: the directional movement measure, $(1 / n) \Sigma\left(\log y_{2 i}-\log y_{1 i}\right)$, and mobility as welfare changes, which both go from being positive when Gates gains to being negative when Gates loses. Unfortunately, these sign changes are the exact opposite of what would be required by conditions i) - iii).

We may conclude that these income mobility measures do not adequately distinguish between income change processes that equalize longer-term incomes and those that disequalize them. This criticism needs to be put in context: these other measures adequately measure the concepts they were designed to measure; what they do not adequately measure is this concept, viz., mobility as an equalizer of longer-term 
incomes relative to base year incomes. This insensitivity is what motivates the development in this paper of a new class of measures - ones that do distinguish between equalizing and disequalizing mobility processes.

Before proceeding, a remark is in order on the distinction between the notion of mobility as an equalizer of longer-term incomes, which is the concern here, versus the notion of mobility as an equalizer of opportunity, which is one way of looking at timeindependence (Bénabou and Ok, 2001). Consider the following example. Let there be a group of $n$ identical individuals, each with the same base-year income, who pool their money into a winner-take-all lottery.. Assume that this is a fair lottery so that each participant has a one-n'th chance of winning. In the sense of equality of opportunity, establishing such a lottery is equalizing - in fact, perfectly equal - because final year income opportunities are equal ex ante for everyone. However, in the sense we are discussing here, the winner-take-all mobility process is disequalizing, because the average incomes before and after the lottery are more unequally distributed than were initial incomes. The distinction between mobility as an equalizer of ex ante opportunities and mobility as an equalizer of ex post outcomes is important; it is the latter that we will look at in what follows.

\section{Indices of Mobility as Equalization of Longer-Term Incomes}

\subsection{Toward a New Class of Measures}

The properties of mobility measures have been formalized for many years starting with the work of Shorrocks (1978), King (1983), and Cowell (1985); these and other contributions are surveyed in Shorrocks (1993), Maasoumi (1998), and Fields and Ok (1999a). In this section, I develop properties that would be desirable for a measure of mobility as an equalizer of longer-term incomes to possess and demonstrate a class of measures consistent with these properties. 
As before, let $y_{i}^{t}$ denote the income of individual $\mathrm{i}$ in time period t. Let $\ell_{i}$ be a measure of the longer-term economic well-being of person i and let $\iota_{i}$ be a measure of i's shorter-term economic well-being, with corresponding n-vectors $\ell \equiv\left(\ell_{1}, \ldots \ell_{n}\right)$ and $\triangleleft \equiv\left(\iota_{1}, \ldots \iota_{n}\right)$ in the population as a whole. $I(\ell)$ and $I(\triangleleft)$ are measures of inequality of $\ell$ and $₫$ respectively.

If our interest were merely in ordinal comparisons - that is, whether mobility has been equalizing or disequalizing of longer-term incomes -- we could choose criteria for inequality comparisons such as the Lorenz criteria applied to the vectors $\ell$ and $\iota$. Our concern, though, goes beyond that to the question of how equalizing or disequalizing is income mobility. For this question, cardinal indices are required.

The crucial concept in what follows is an equalization function. This function, denoted $E_{\ell, \iota}=E(I(\ell), I(\triangleleft))$ tells us how much more or less equal is the distribution of economic well-being in the long-term compared with economic well-being in the shortterm. Of course, it is the nature and extent of economic mobility that determines whether equalization or disequalization takes place over time.

\subsection{Specifying the Equalization Function}

The equalization function $E(I(\ell), I(c))$ is assumed to have the following properties

P1. Normalization. $I(\ell)=I(\triangleleft) \Rightarrow E(I(\ell), I(\triangleleft))=0$.

P2. Equalization. $I(\ell)<I(\triangleleft) \Rightarrow E(I(\ell), I(\triangleleft))>0$.

P3. Disqualization. $I(\ell)>I(\triangleleft) \Rightarrow E(I(\ell), I(\triangleleft))<0$.

\section{P4. Greater Equalization.}

a. For two alternative $\ell$ vectors $\ell_{1}, \ell_{2} \in \mathcal{L}$ and a given vector $\_\in S$,

$$
I\left(\ell_{1}\right)<I\left(\ell_{2}\right)<I(\triangleleft) \Rightarrow E_{\iota, a}>E_{\iota, 12} .
$$

b. For two alternative $₫$ vectors $s_{1}, s_{2} \in S$ and a given vector $\ell \in \mathcal{L}$,

$$
I\left(\iota_{1}\right)>I\left(\alpha_{2}\right)>I(\ell) \Rightarrow E_{\iota, \iota}>E_{\alpha 2, \iota} .
$$




\section{P5. Greater Disequalization.}

a. For two alternative $\ell$ vectors $\ell_{1}, \ell_{2} \in \mathcal{L}$ and a given vector $\_\in S$,

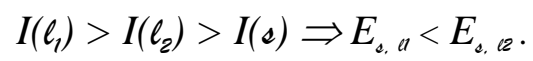

b. For two alternative $₫$ vectors $s_{1}, s_{2} \in S$ and a given vector $\ell \in \mathcal{L}$,

$$
I(\ell)>I\left(\iota_{1}\right)>I\left(\iota_{2}\right) \Rightarrow E_{\triangleleft 2, \iota}>E_{\lrcorner l, \iota} .
$$

What follows immediately from P1-P5 is that they imply that the equalization function $E(I(\ell), I(\triangleleft))$ is
a) decreasing in $I(\ell)$,
b) increasing in $I($ ()),
c) equal to zero when $I(\ell)=I(\triangleleft)$.

The class of mobility measures consistent with this class of equalization functions is very broad. What remains to be specified is i) how $I(\ell)$ and $I(\triangleleft)$ are to be combined in the $E(I(\ell), I(\iota))$ function, ii) how long-term incomes $\ell=\left(\ell_{1}, \ldots, \ell_{n}\right)$ and short-term incomes $₫=\left(\iota_{1}, \ldots, s_{n}\right)$ are to be defined, and iii) which inequality measure or measures are to be used.

\subsection{Particularizing the Equalization Function}

The particular class of equalization indexes $\mathcal{\varepsilon}$ used below makes the following additional judgments:

Combining $I(\ell)$ and $I(\triangleleft)$. Let the function combining $I(\ell)$ and $I(\triangleleft)$ be the ratio function. The ratio function accords with the judgment usually made in inequality analysis that inequality is relative. By defining $E(I(\ell), I(\triangleleft))$ as $\hat{E}(I(\ell) / I(\triangleleft))$, we are able to impose the judgment that equalization also is relative. Thus, there would be the same amount of equalization in $(100,200,20000) \rightarrow(100,200,10000)$ as there would be in $(200,400,40000) \rightarrow(200,400,20000)$.

Defining Short-Term Income. Let the measure of short-term income s to be used be income in the base year. As already noted, this choice accords with standard 
practice in economics of starting with an initial value (such as base year GNP) and then looking at the subsequent change in a variable of interest (such as economic growth). In order to specify which single year is to be used as the reference year, let us take, as in the examples above, the distribution of income in the first year as our reference period, as has been done, for example, by Chakravarty, Dutta, and Weymark (1985) and Ruiz-Castillo (2004). In this way, the mobility measure then tells us how the inequality of longer-term income compares with the inequality of first-year income, a natural choice given the propensity to frame discussions of change with reference to initial conditions.

Defining Long-Term Income. Let long-term income $\ell$ be the mean of base-year income and final-year income. Simple averaging has a long history in economic analyses of longer-term economic well-being, going back to Friedman (1957) and also including Shorrocks (1978), Chakravarty, Dutta and Weymark (1985), Maasoumi and Zandvakili (1989), and Ruiz-Castillo (2004), among many others. Averaging is chosen here purely for convenience. The alternative to averaging is to follow the line of work of Atkinson and Bourguignon (1982), Maasoumi (1986), Tsui (1995), and Gottschalk and Spolaore (2002) and build in a measure of long-term economic well-being $\ell$ that incorporates imperfect substitutability. Maasoumi and Zandvakili (1990) calculate empirical mobility estimates using both simple averaging and imperfect substitutability. Lillard (1977) and Atkinson, Bourguignon, and Morrisson (1992) note the important role that capital markets play in justifying or failing to justify the use of averages.

Choosing an Inequality Measure. Finally, let us choose a Lorenzconsistent inequality measure such as the Gini coefficient or the Theil index. This too is the established tradition in economics (Sen, 1973; Atkinson, 1983). 


\subsection{The Resultant Class of Indices}

Given these choices, the following class of measures of mobility as an equalizer of longer-term incomes is obtained:

$$
\varepsilon \equiv 1-(I(a) / I(y)))
$$

where $a$ is the vector of average incomes, $y$ is the vector of base-year incomes, and $I($.$) is$ a Lorenz-consistent inequality measure such as the Gini coefficient or the Theil index. I(.) may also be additively decomposable, which the Theil index is and the Gini coefficient is not. The measure $\varepsilon$ is an index of equalization in the sense that a positive value indicates that average incomes a are more equally distributed than base-year incomes $q 1$, a negative value indicates that $a$ is less equally distributed than $q 1$, and a zero value that $a$ and $q 1$ are distributed equally unequally.

\subsection{The $\varepsilon$ Index Compared with the Chakravarty, Dutta, and Weymark}

\section{Index}

The class of equalization measures

$$
\varepsilon \equiv 1-(I(a) / I(y))
$$

is equivalent to the family of mobility measures derived by Chakravarty, Dutta, and Weymark (1985):

$$
M_{C D W} \equiv\left(E\left(y_{\text {agg }}\right) / E(y)\right)-1,
$$

where $E($.$) is an equality measure,$ yagg $_{\text {a }}$ is aggregate income over the observation period, and $y$ is income in the first period. However, CDW and I see the welfare economics of our indices differently from one another, for reasons to be explained in Section 5.

Other differences between my view and CDW's, though less fundamental, are still noteworthy. One is that the concept I seek to measure is the extent to which mobility equalizes longer-term incomes relative to inequality in the first year and not relative to a hypothetical path. Another is that the class of indices they develop is an ethical one. By contrast, the class I derive in this paper is a descriptive one; in CDW's words, descriptive 
indices "endeavor to measure some objective aspect of mobility." Their purpose, they say, is to supplement the descriptive approach, not supplant it. This distinction parallels the difference between Atkinson's (1970) "ethical" approach to inequality measurement as compared with Sen's (1973) "descriptive" approach.

\subsection{The $\varepsilon$ Index Compared with Shorrocks's $M_{S}$.}

As noted above, Shorrocks (1978) conceptualized income mobility as the degree to which income equalization occurs as the observation period is lengthened. For Shorrocks, mobility is the opposite of rigidity, defined as follows. For the case of $T$ annual observations on income, his rigidity index compares the inequality of $T$-period incomes with the inequality of single-period incomes. As above, let $y_{i}^{t}$ denote the income of individual $i$ at time $t$ and $\mathbf{y}^{t}:=\left[\begin{array}{c}y_{1}^{t} \\ \cdot \\ \cdot \\ y_{n}^{t}\end{array}\right]$ be the vector of such incomes in the population. Similarly, let $Y_{i}:=\sum_{t=1}^{T} y_{i}^{t}$ to be the total income received by individual $i$ over $T$ periods and $\mathbf{Y}:=\left[\begin{array}{c}Y_{1} \\ \cdot \\ \cdot \\ Y_{n}\end{array}\right]$ be the distribution of these longer-term incomes. Shorrocks's rigidity index has in the numerator the inequality of $T$-period incomes using an inequality measure $I($.$) , and in the denominator a weighted average of the inequalities in each year,$ with the weights being the ratio of the mean income in that year to the mean income over $T$ years:

$$
R=\frac{I(\mathbf{Y})}{\frac{1}{T} \sum_{t=1}^{T} w^{t} I\left(y^{t}\right)}=\frac{I(\mathbf{Y})}{\frac{1}{T} \sum_{t=1}^{T} \frac{\mu^{t}}{\mu^{T}} I\left(y^{t}\right)} .
$$

Shorrocks's mobility measure is then $M_{S} \equiv 1-R$. 
Bénabou and Ok (2001) noted a feature of Shorrocks's measure which they regard as problematical and may strike other observers likewise: $M_{S}$ treats equalizing and disequalizing changes in essentially identical fashion. This point can be illustrated by calculating $M_{S}$ in the preceding examples, using the Gini coefficient as the index of inequality. The Gates-gains mobility process $(100,200,20000) \rightarrow(100,200,30000)$ produces a value for $M_{S}$ of $4.99 \times 10^{-5}$, while the Gates-loses mobility process $(100,200,20000) \rightarrow(100,200,10000)$ produces the index value $5.91 \times 10^{-5}$. Naturally, had all incomes remained unchanged at $(100,200,20000), M_{S}$ would have been equal to zero. $M_{S}$ therefore ranks these three processes, in order of mobility, as: "Gates loses," then "Gates gains," and finally "no change." Thus, neither the sign nor the relative magnitudes of $M_{S}$ conveys any information about whether the mobility process is an equalizing or a disequalizing one. This is because $M_{S}$ does not satisfy the preceding equalization properties.

To repeat, Shorrocks's $M_{S}$ index was not intended to quantify the direction and the extent of the difference between the inequality of longer-term income and the inequality of base year income, so the fact that his index does not measure this difference is not a criticism of Shorrocks - I bring it up here merely to show how the $M_{S}$ index differs from the $\varepsilon$ index derived above.

\section{Applications of the New Index}

In this section, three applications of the new equalization measure $\mathcal{E} \equiv 1-(I(a) / I(q 1))$ shall be presented.

The first is the application to the hypothetical situations of "Gates gains" and "Gates loses" presented above. All indices satisfying the equalization properties P1-P5 including $\mathcal{E}=1-\left(I(a) / I\left(y_{1}\right)\right.$, have a threshold value of zero, meaning that positive values signify that longer-term incomes are more equal than base-year incomes, while negative values signify the opposite. For the "Gates gains" mobility process 
$(100,200,20000) \rightarrow(100,200,30000)$, the $\varepsilon$ index is equal to $-3.9 \times 10^{-3}$, while for the "Gates loses" process $(100,200,20000) \rightarrow(100,200,10000)$, the value of the index is $+6.6 \times 10^{-3}$. The change in sign of the $\varepsilon$ index from negative to positive clearly shows that the Gates-gains process is disequalizing while the Gates-loses process is equalizing.

As a second application, the $\varepsilon$ index is used to measure the extent to which fiveyear income mobility has equalized the distribution of longer-term labor earnings in the United States. Building on prior work by Fields, Leary, and Ok (2000, 2002), for each five-year period between 1970 and 1995, base-year and final-year labor earnings (including overtime and bonuses) are drawn from the Panel Study of Income Dynamics. For each panel, the sample consists of men aged 25-60 in the base year who were not students, retired, or self-employed, and who had positive earnings in both years. Because the extent of labor earnings mobility may be sensitive to the particular base year and terminal year chosen, as a robustness check, calculations were made for each five-year period starting and ending a year earlier. For the U.S. case, the inequality index I(.) used in calculating $\varepsilon$ is the Gini coefficient.

As shown in Table 2, two striking findings emerge from this initial exploration: (1) Five-year earnings mobility in the United States was equalizing in the 1970s but not in the 1980s and 1990s. This is a brand new finding: no other researcher, to the best of my knowledge, has shown that income mobility in the United States stopped equalizing longer-term incomes around 1980. This finding should be regarded as tentative and deserves to be subjected to sensitivity tests in future work. (2) Other mobility concepts using the same data are plotted in Table 3 . We see that their time paths are entirely different from the time path of the $\varepsilon$ index. The indices used to gauge time-independence, positional movement, share movement, and non-directional income movement all show an inverted-U pattern, while directional income movement exhibits a wiggle which is always positive. Only the $\varepsilon$ index changes sign from positive to negative. 
The third application is to two-year earnings mobility in France. Buchinsky, Fields, Fougère, and Kramarz (2003) used data from employers' declarations of wages paid to each of their employees (Déclarations Annuelles de Salaires) to calculate the time paths of various indices of earnings mobility of full-time workers for two-year intervals from 1967-69 to 1995-97. In the French case, $\varepsilon$ is calculated using the Theil index for I(.) because of the authors' collective preference for an additively decomposable inequality index.

Three principal findings were reached for France: (1) The $\varepsilon$ index for France, shown in Table 4, is never negative. Thus, in France, unlike the United States, income mobility has equalized longer-term incomes throughout the observation period. (2) The $\varepsilon$ index shares a U-shape with measures of many other mobility concepts in France (Table 5). But: (3) Unlike many of the other U-shaped indices, the $\varepsilon$-index attained its maximum in the most recent period. France is unlike the United States in this respect; in the U.S., mobility as an equalizer of longer-term incomes exhibits a quite different path from measures of other mobility concepts.

These applications show that in practice as well as in theory, the concept of mobility-as-an-equalizer-of-longer-term-incomes is fundamentally different from other mobility concepts.

\section{Using the Equalization Index in Social Welfare Judgments}

Up to now, the principal contribution of this paper has been to derive a class of indices of a well-established but hitherto unmeasured aspect of income mobility: mobility as an equalizer of longer-term incomes relative to initial incomes. Now that this concept has a defensible measure - actually a broad class of such measures - the question can be asked, how much weight should this measure receive in social welfare judgments? Specifically, how much weight should be given to equalization relative to time- 
independence, positional movement, share movement, non-directional income movement, and directional income movement?

The answer is necessarily subjective depending on the preferences of the evaluator, but let me state mine. For me, an appealing social welfare function in a panel data context would be to regard economic well-being $(W)$ as a positive function of the extent of directional income movement $\left(M_{\text {dir }}\right)$ and of mobility as an equalizer of longerterm incomes relative to initial incomes $(\varepsilon)$ :

$$
W=f\left(M_{\text {dir }}, \varepsilon\right), \Delta W / \Delta m_{\text {dir }}>0, \Delta W / \Delta \varepsilon>0 .
$$

The positive weight given to directional income movement can be thought of as an economist's preference for efficiency, while the positive weight given to equalization can be thought of as an economist's preference for equity.

The efficiency judgment $\Delta W / \Delta m_{d i r}>0$ in (1) takes us beyond the bounds of this paper. However, the equity judgment $\Delta W / \Delta \varepsilon>0$ bears further scrutiny.

Atkinson (1980) and Atkinson and Bourguignon (1982) argued explicitly for the ethical case in favor of a more equal distribution of longer-term incomes. Let an evaluator adopt a social valuation function whereby the social valuation of recipient i's income in period $j$ is a decreasing function of $i$ 's income in period $k$ - that is, the higher is the recipient's income in one year, the lower is the marginal value of a given income amount in the other year. Thus, letting $y_{i}^{1}$ and $y_{i}^{2}$ denote base-year and final-year income respectively, in the two period case, $V=V\left(y_{i}^{1}, y_{i}^{2}\right)$ with $V_{12}<0$. It follows that for given marginal distributions of base-year incomes

$\mathbf{y}^{1}=\left[\begin{array}{c}y_{1}^{1} \\ \cdot \\ \cdot \\ y_{n}^{1}\end{array}\right]$ and final-year incomes $\mathbf{y}^{2}=\left[\begin{array}{c}y_{1}^{2} \\ \cdot \\ \cdot \\ y_{n}^{2}\end{array}\right]$, all social valuation functions of the form $V=V\left(y_{i}^{1}, y_{i}^{2}\right)$ with $V_{12}<0$ would judge that the more equalization of longer-term incomes there is through income mobility, the better the economy is performing. 
Shorrocks (1978) reached a similar conclusion. He wrote: "If two societies have identical income distributions in each year, then social welfare will be greater for the society which exhibits more mobility.” What Shorrocks favored was more mobility within a given structure of single-year distributions. What he was silent about, and what social welfare function (1) addresses explicitly, is how to consider mobility which involves a change in the structure itself, as in the Gates-gains and Gates-loses cases.

Two objections can be raised to social welfare function (1). The first is that it has too much in it. The second is that it has too little.

Let us start with the view that (1) contains too much. Above, I noted that the equalization index $\varepsilon$ developed in this paper and the Chakravarty-Dutta-Weymark index $M_{C D W}$ are essentially equivalent from a purely positive point of view. A referee has helpfully pointed out that the precise relationship between them is $\mathrm{E}\left(\mathbf{y}_{1}-->\mathbf{y}_{2}\right)=$ $\left[\left(1-\mathrm{I}\left(\mathbf{y}_{1}\right)\right) / \mathrm{I}\left(\mathbf{y}_{\mathbf{1}}\right)\right] \mathrm{M}_{\mathrm{CDW}}\left(\mathbf{y}_{\mathbf{1}}-->\mathbf{y}_{2}\right)$. Because $\mathrm{I}\left(\mathbf{y}_{\mathbf{1}}\right)$ is an inequality index, which like the Gini is usually normed so that it falls between zero and one, $\mathrm{I}\left(\mathbf{y}_{\mathbf{1}}\right)$ is expected to be less than one. Therefore $\left[\left(1-\mathrm{I}\left(\mathbf{y}_{1}\right)\right) / \mathrm{I}\left(\mathbf{y}_{1}\right)\right]$ is always positive and $M_{\mathrm{CDW}}\left(\mathbf{y}_{\mathbf{1}}-->\mathbf{y}_{2}\right)$ and $\mathrm{E}\left(\mathbf{y}_{1} \boldsymbol{- -}^{->} \mathbf{y}_{\mathbf{2}}\right)$ always have the same sign. Hence, when mobility equalizes (disequalizes) longer-term incomes, $\mathrm{M}_{\mathrm{CDW}}\left(\mathbf{y}_{1}-->\mathbf{y}_{2}\right)$ evaluates the process positively (negatively) regardless of growth.

My normative view is quite different from CDW's. In their words (p. 1): "Ethical indices of income mobility measure the change in welfare resulting from mobility. The concept of mobility we explore consists of a welfare comparison between the actual time path of the income distribution with a hypothetical time path obtained by supposing that starting from the actual first-period distribution, the remaining income receipts exhibit complete immobility." CDW's domain $D$ is the positive orthant. This domain is not restricted to distributions with the same marginal distributions or the same mean, and indeed CDW explicitly allow the mean income to change. But when the mean changes, "the change in welfare resulting from mobility" should, in my judgment, depend on the 
direction and amount by which the mean changes and not just on whether the mobility is equalizing or disequalizing. CDW say (p. 8): "Socially desirable mobility is associated with income structures having positive index values while socially undesirable mobility is associated with income structures having negative index values." In effect, then, their social welfare function is

$$
W=g\left(M_{C D W}\right), \Delta W / \Delta M_{C D W}>0 .
$$

Note the omission of the directional movement component as compared with (1).

The welfare function (2) gives a clear verdict: it evaluates the Gates-gains process $(100,200,20000) \rightarrow(100,200,30000)$ negatively and the Gates-loses process $(100,200,20000) \rightarrow(100,200,10000)$ positively. Such evaluations are in direct contradiction to the quasi-Paretian welfare judgment, viz., that an increase in one income, holding other incomes constant, raises social welfare. While ethical judgments are in the eyes of the evaluator, in my view, the CDW welfare judgment gives too much ethical weight to the disequalizing aspect of the pattern of income growth and too little to the fact that income has grown when Gates gains and contracted when Gates loses.

Other observers might object to (1) for the opposite reason: that the function should also include measures of time-independence, positional movement, share movement, or non-directional income movement as additional arguments. I have not included these as arguments in my own social welfare judgments because these considerations do not have any obvious welfare content for me. This is because I can think of reasons why an increase in time-independence, positional movement, share movement, or non-directional income movement could be given positive social welfare weight and others why they might be given negative social welfare weight.

Readers are encouraged to think carefully about what social welfare functions they want to use and then measure those aspects of income mobility that are of greatest concern to them. What I have tried to highlight in this section is that a reasonable case can be made that our welfare judgments should include mobility as an equalizer of 
longer-term incomes relative to initial incomes as one of the arguments in a social welfare function.

\section{Conclusion}

This paper has made five points. First, a well-established concept in the income mobility literature is the notion of mobility as an equalizer of longer-term incomes relative to base-year incomes. Second, although the mobility measures in common use measure other mobility concepts, they do not adequately measure this one. Third, a set of axioms has been formulated leading to a class of indices of mobility as an equalizer of longer-term incomes, one easily-implementable subclass of which is the equalization index $\varepsilon=1-\left(I(a) / I\left(y_{1}\right)\right.$, where $I(a)$ and $I\left(y_{1}\right)$ are respectively the inequality of average income and of base-year income. The new index is similar to one existing mobility index though its use is different, and different from other indices. Fourth, in empirical work for the United States and France, the $\mathcal{E}$ index makes a fundamental qualitative difference. The new findings here are that income mobility equalized longer-term earnings among U.S. men in the 1970s but not in the 1980s or 1990s, whereas in France, income mobility has always been equalizing since first measured in the late 1960s, and furthermore the degree of equalization is higher in more recent years than it ever was before. Fifth and finally, the equalization index $\varepsilon$ deserves consideration as one component of an observer's social welfare function.

The concept of mobility as an equalizer of longer-term incomes is an old one, complementing mobility-as-time-independence, positional movement, share movement, non-directional income movement, and directional income movement. Mobility analysts would do well to be careful to specify which of these concepts are of greatest interest to them and to choose the mobility indices they use accordingly. 


\section{REFERENCES}

Atkinson, A.B., 1980. The Measurement of Economic Mobility. In P.J. Eijgelshoen and L.J. van Gemerden, eds, Inkomensverdeling en Openbare Financién (Utrecht: Het Spectrum).

Atkinson, A.B., 1983. The Economics of Inequality. (Oxford: The Clarendon Press).

Atkinson, A.B. and F. Bourguignon, 1982. The Comparison of Multi-Dimensioned Distributions of Economic Status, Review of Economic Studies XLIX, 183-201.

Atkinson, A.B., F. Bourguignon, and C. Morrisson, 1992. Empirical Studies of Earnings Mobility. (Chur, Switzerland: Harwood).

Bénabou, R. and E.A. Ok, 2001. Mobility as Progressivity: Ranking Income Processes According to Equality of Opportunity, National Bureau of Economic Research, Working Paper \#8431, processed.

Buchinsky, M., G.S. Fields, D. Fougère, and F. Kramarz, 2003. Francs or Ranks? Earnings Mobility in France, 1967-1999, CREST, processed.

Chakravarty, S.R., B. Dutta, and J.A. Weymark, 1985. Ethical Indices of Income Mobility. Social Choice and Welfare 2, 1-21.

Cowell, F.A., 1985. Measures of Distributional Change: An Axiomatic Approach. Review of Economic Studies 52: 135-151. 
Fields, G.S., 2001. Distribution and Development: A New Look at the Developing World. (Cambridge, MA: MIT Press and Russell Sage Foundation).

Fields, G.S., 2008. Income Mobility, in L. Blume and S. Durlauf, eds., The New Palgrave.

Fields, G.S., J.B. Leary, and E.A. Ok, 2000. Dollars and Deciles: Changing Earnings Mobility in the United States, 1970-1995, Cornell University, processed.

Fields, G.S., J.B. Leary, and E.A. Ok, 2002. Stochastic Dominance in Mobility Analysis. Economics Letters 75: 333-339.

Fields, G.S. and E.A. Ok, 1999a. The Measurement of Income Mobility. In J. Silber, ed., Handbook of Income Distribution Measurement. (Boston: Kluwer).

Fields, G.S. and E.A. Ok, 1999b. Measuring Movement of Income. Economica 66, 455472.

Friedman, M., 1957. A Theory of the Consumption Function. (Princeton: Princeton University Press).

Friedman, M., 1962. Capitalism and Freedom. (Chicago: University of Chicago Press).

Gottschalk, P. and E. Spolaore, 2002. On the Evaluation of Economic Mobility. Review of Economic Studies. 69: 191-208. 
Jarvis, S. and S. P. Jenkins, 1998. How Much Income Mobility Is There in Britain? The Economic Journal 108, 1-16.

Krugman, P., 1992. The Rich, the Right, and the Facts. The American Prospect. 11, 1931.

Lambert, P., 2001. The Distribution and Redistribution of Income. (Manchester: University of Manchester Press).

Lillard, L., 1977. The Distribution of Earnings and Human Wealth in a Life-Cycle Context, in T. Juster, ed., The Distribution of Economic Well-Being. (Cambridge, MA: NBER).

Maasoumi, E., 1986. The Measurement and Decomposition of Multi-Dimensional Inequality. Econometrica 54: 991-997.

Maasoumi, E., 1998. On Mobility, in D. Giles and A. Ullah, eds., Handbook of Applied Economic Statistics, Marcel Dekker, 119-176.

Maasoumi, E. and S. Zandvakili, 1989. Mobility Profiles and Time Aggregates of Individual Incomes. Research on Economic Inequality, 195-218.

Maasoumi, E. and S. Zandvakili, 1990. Generalized Entropy Measures of Mobility for Different Sexes and Income Levels. Journal of Econometrics 43: 121-133.

Morgan, S.L., 2005. Past Themes and Future Prospects for Research on Social and Economic Mobility, in S.P. Morgan, D.B. Grusky, and G.S. Fields, eds., Mobility and 
Inequality: Frontiers of Research from Sociology and Economics, Stanford University Press.

Ruiz-Castillo, J., 2004. The Measurement of Structural and Exchange Mobility. Journal of Economic Inequality 2: 219-228.

Sawhill, I. V. and M. Condon, 1992. Is U.S. Income Inequality Really Growing? Policy Bites 13, 1-4.

Schumpeter, J., 1955. Imperialism and Social Classes. (New York: Meridian Books).

Sen, A.K., 1973. On Economic Inequality. (New York: Norton).

Shorrocks, A. F., 1978. Income Inequality and Income Mobility, Journal of Economic Theory 19, 376-393.

Shorrocks, A.F., 1993. On the Hart Measure of Income Mobility. In M. Casson and J. Creedy, eds., Industrial Concentration and Economic Inequality. (Cambridge: Edward Elgar).

Slemrod, J., 1992. Taxation and Inequality: A Time-Exposure Perspective, in: J.M. Poterba, ed., Tax Policy and the Economy, Vol. 6 (Cambridge, MA: MIT Press for the NBER) 105-127.

Tsui, K.Y., 1995. Multidimensional Generalizations of the Relative and Absolute Inequality Indices: The Atkinson-Kolm-Sen Approach, Journal of Economic Theory 67, 251-265. 
Table 1.

Measures of Six Mobility Concepts When Longer-Term Incomes are Disequalized and When They Are Equalized.

\begin{tabular}{|c|c|c|}
\hline Measure & $\begin{array}{c}\text { Disequalizing Process: } \\
\text { The richest person gains } 50 \% \\
(100,200,20000) \rightarrow \\
(100,200,30000) \\
\text { ("Gates Gains") } \\
\text { (1) }\end{array}$ & $\begin{array}{c}\text { Equalizing Process: } \\
\text { The richest person loses } 50 \% \\
(100,200,20000) \rightarrow \\
(100,200,10000) \\
\text { ("Gates Loses") } \\
(2)\end{array}$ \\
\hline $\begin{array}{l}\text { (a) Time-independence, as measured by } 1-r\left(y_{1}, y_{2}\right) \text {, } \\
\text { where } r \text { is the Pearson correlation coefficient }\end{array}$ & $1.068 \times 10^{-6}$ & $9.808 \times 10^{-6}$ \\
\hline $\begin{array}{l}\text { (b) Positional-movement, as measured by } \\
1-\rho\left(y_{1}, y_{2}\right) \text {, where } \rho \text { is the rank correlation } \\
\text { coefficient }\end{array}$ & 0 & 0 \\
\hline $\begin{array}{l}\text { (c) Per-capita share movement, as measured by } \\
\text { (1/n) } \sum\left|s\left(y_{2 i}\right)-s\left(y_{1 i}\right)\right| \text {, where } s(.) \text { denotes i's share of } \\
\text { total income }\end{array}$ & $3.252 \times 10^{-3}$ & $9.565 \times 10^{-3}$ \\
\hline $\begin{array}{l}\text { (d) Per-capita non-directional income movement, as } \\
\text { measured by }(1 / \mathrm{n}) \Sigma\left|\mathrm{y}_{2 \mathrm{i}}-\mathrm{y}_{1 \mathrm{i}}\right|\end{array}$ & 3333.3 & 3333.3 \\
\hline $\begin{array}{l}\text { (e) Per-capita directional income movement, as } \\
\text { measured by }(1 / n) \sum\left(\log y_{2 \mathrm{i}}-\log \mathrm{y}_{1 \mathrm{i}}\right)\end{array}$ & 0.135 & -0.231 \\
\hline (f) Mobility as welfare change & $\begin{array}{l}\text { Positive for any welfare function that is } \\
\text { increasing in all incomes }\end{array}$ & $\begin{array}{l}\text { Negative for any welfare function that is } \\
\text { increasing in all incomes }\end{array}$ \\
\hline
\end{tabular}


Table 2.

Mobility as Equalization in the U.S. Panel Study of Income Dynamics, 1970-1975 to 1990-1995 and 1969-1974 to 1989-1994,

Measuring Equalization as $\varepsilon=1-\left(\mathbf{G}(a) / G\left(y_{1}\right)\right.$.

\begin{tabular}{||c|c||c|c||}
\hline \hline Period & Value of $\mathcal{E}$ & Period & Value of $\mathcal{E}$ \\
\hline $1970-1975$ & .008 & $1969-1974$ & .014 \\
\hline $1975-1980$ & .020 & $1974-1979$ & .038 \\
\hline $1980-1985$ & -.006 & $1979-1984$ & -.015 \\
\hline $1985-1990$ & -.018 & $1984-1989$ & -.006 \\
\hline $1990-1995$ & .004 & $1989-1994$ & -.005 \\
\hline
\end{tabular}

E-Measure in Each of Five Periods 1970-75 to 1990-95

(Base Year Indicated in the Graph)

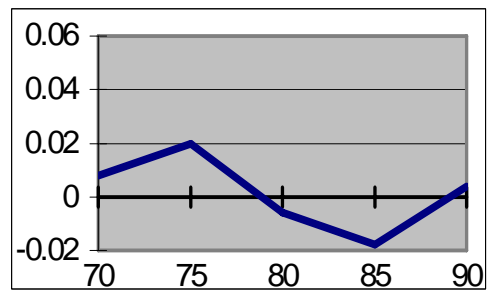

E-Measure in Each of Five Periods

1969-74 to 1989-94

(Base Year Indicated in the Graph)

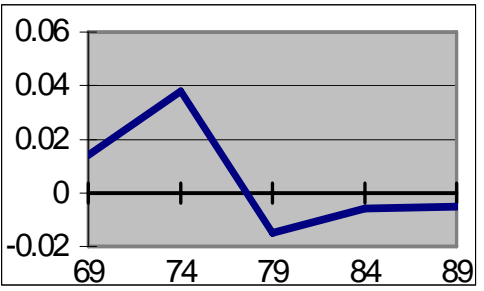

Source: Author's calculations. 
Table 3.

Time Paths of Measures of Other Mobility Concepts in the U.S. Panel Study of Income Dynamics.

1970-1975 to 1990-1995

(Base Year Indicated in the Graphs)

Concept

Positional Movement
Measure

Time Path

Mean absolute centile change

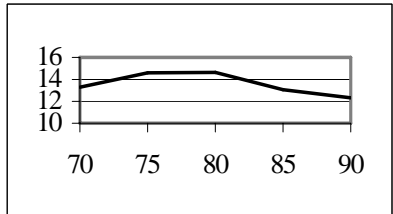

Centile mobility ratio

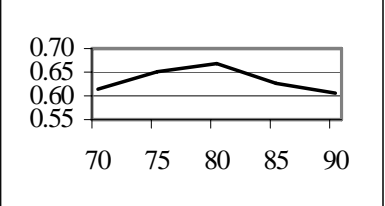

One minus centile

correlation coefficient

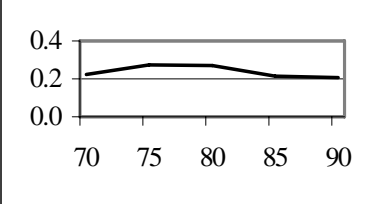

Share Movement

Mean absolute share change

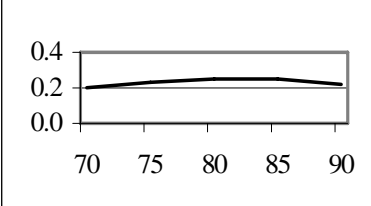

Shorrocks's M(Gini)

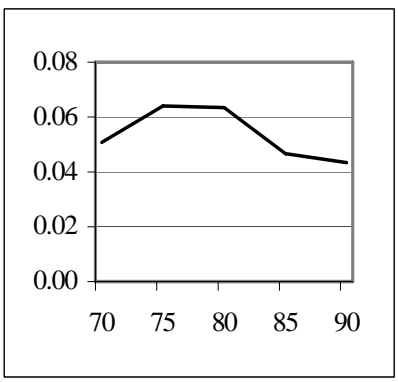




\section{Concept}

\section{Non-Directional Income Movement}

A. In dollars

F-O 1

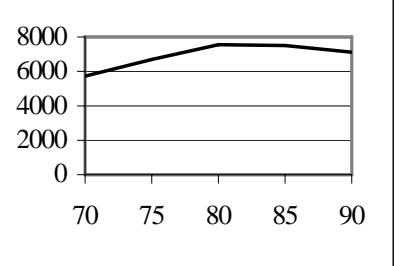

B. In log-dollars

F-O 2

Per-capita growth

B. In log-dollars

Measure

Time Path

\section{Directional Income Movement}

A. In dollars

F-O 3
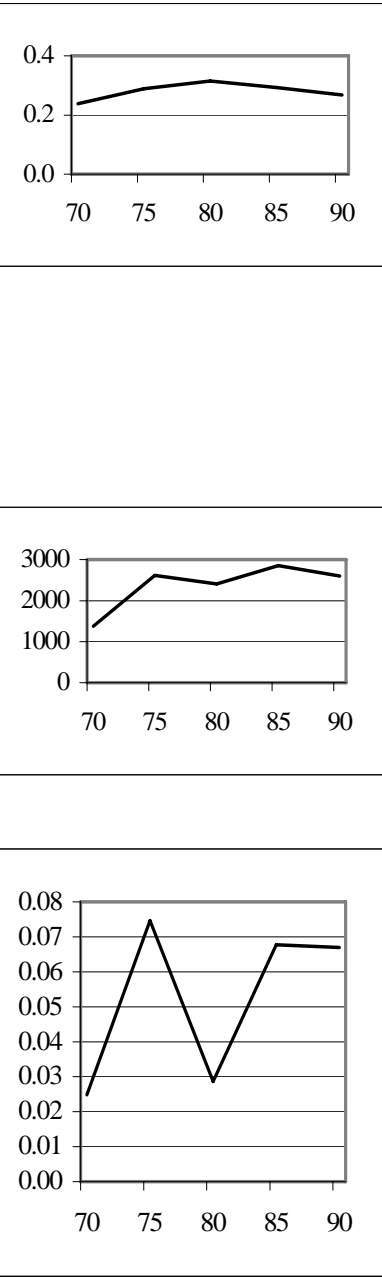


\section{Time-Independence}

A. Of income

B. Of ranks

Negative chi-square

in deciles

One minus rank

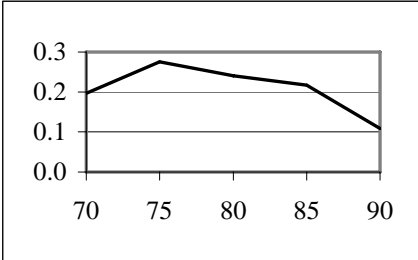
correlation coefficient
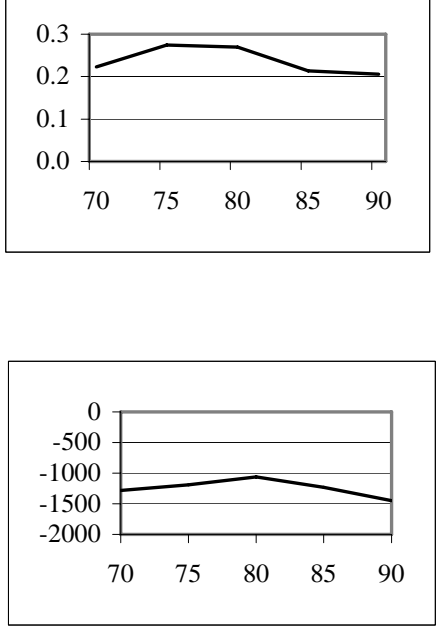

Source: Fields, Leary, and Ok (2000) 
Table 4.

Mobility as Equalization in the French Déclarations Annuelles de Salaires, 1967-69 to 1995-97,

Measuring Equalization as $\mathcal{E}=1-\left(\mathrm{G}(\mathrm{a}) / \mathrm{G}\left(\mathrm{y}_{1}\right)\right.$.

\begin{tabular}{||c|c||c|c||}
\hline \hline Period & Value of P & Period & Value of P \\
\hline $1968-1970$ & 0.040 & $1967-1969$ & 0.040 \\
\hline $1973-1975$ & 0.031 & $1972-1974$ & 0.032 \\
\hline $1978-1980$ & 0.030 & $1977-1979$ & 0.036 \\
\hline $1983-1985$ & $0.008^{*}$ & $1982-1984$ & 0.018 \\
\hline $1988-1990$ & $0.012^{*}$ & $1987-1989$ & 0.002 \\
\hline $1993-1995$ & 0.054 & $1992-1994$ & 0.021 \\
\hline
\end{tabular}

Evolution of $\varepsilon$-Measure, 1967-69 to 1995-97

(Base Year Indicated in the Graph)

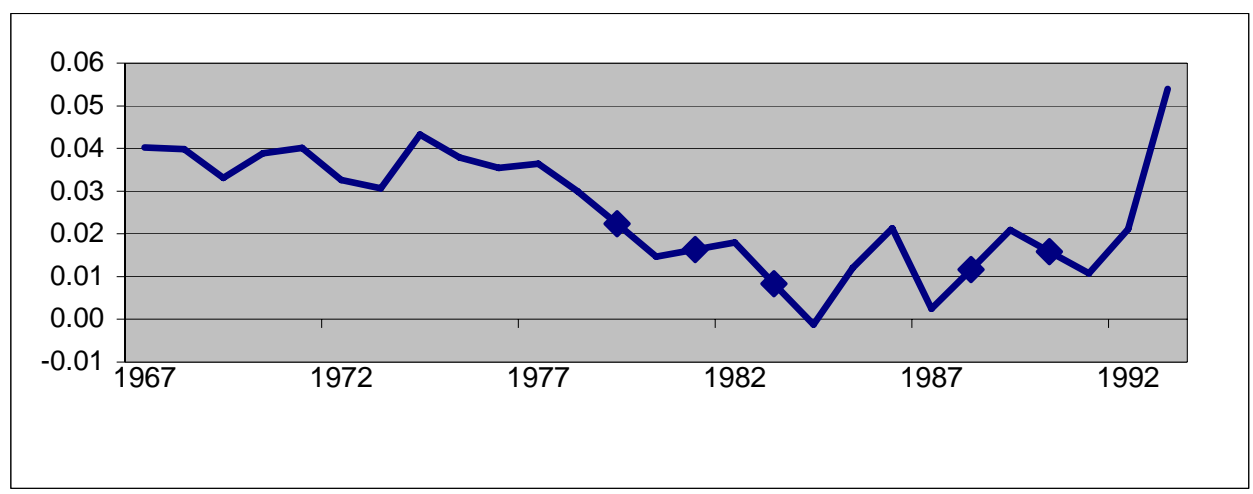

Source: Buchinsky, Fields, Fougère, and Kramarz (2003).

\footnotetext{
* P-Value interpolated from adjacent years due to missing data.
} 
Table 5.

Time Paths of Measures of Other Mobility Concepts

in the French Déclarations Annuelles de Salaires, 1967-69 to 1995-97.

Concept

Positional Movement

Mean absolute centile change

(Base Year Indicated in the Graphs)

Measure

$\underline{\text { Time Path }}$
Share Movement

Mean absolute share change

\section{Non-Directional Income Movement}

In log-dollars

\section{Directional Income Movement}

In log-dollars
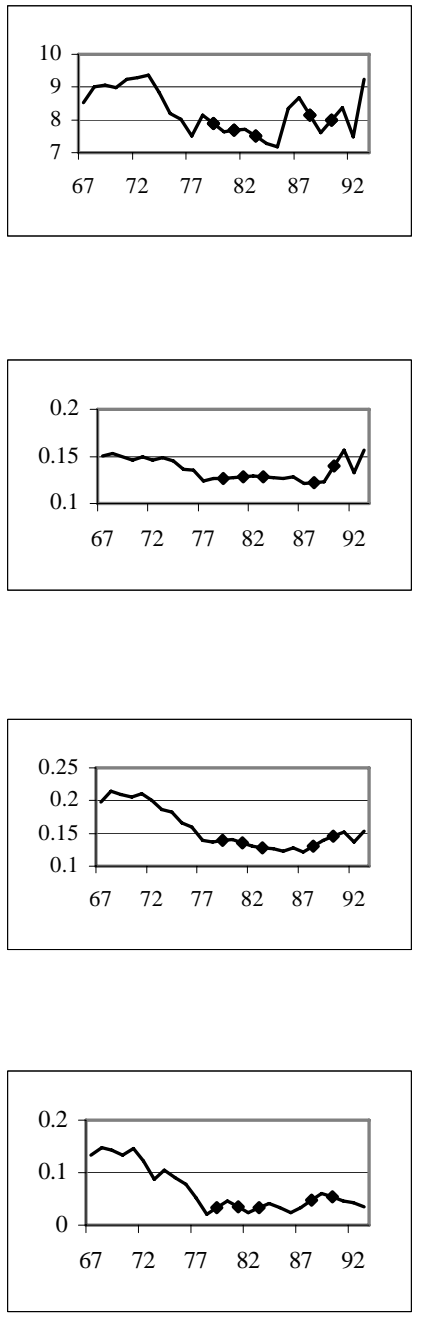


\section{Time-Independence}

Of ranks $\quad$ Negative chi-square

$$
\text { in deciles }
$$

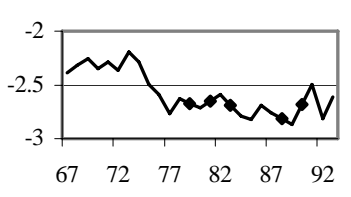

Source: Buchinsky, Fields, Fougère, and Kramarz (2003) 